\title{
Aspectos éticos e o uso de produtos fluorados na visão de lideranças de saúde
}

\section{I ${ }^{1}$ Regina Glaucia Lucena Aguiar Ferreira, ${ }^{2}$ Regina Auxiliadora de Amorim Marques, \\ ${ }^{3}$ Léa Maria Bezerra de Menezes, ${ }^{4}$ Paulo Capel Narvai I}

Resumo: O flúor tem sido empregado na prevenção da cárie dentária, principalmente em águas de abastecimento e dentifrícios. Um efeito indesejável, a fluorose leve, tem suscitado preocupações entre especialistas. Este trabalho descreve as percepçôes dos delegados na $13^{\text {a }}$ Conferência Nacional de Saúde no que se refere aos aspectos éticos relacionados ao uso de substâncias e produtos fluorados. Realizou-se pesquisa exploratória, descritiva, com abordagem qualitativa, utilizando-se como técnica de processamento de depoimentos o Discurso do Sujeito Coletivo (DSC). A população de estudo foi definida por conveniência, e o critério de escolha foi participar da Conferência como delegado. Ao todo, foram 310 respondentes. Os dados foram coletados por meio de questionários semiestruturados e analisados pela análise do discurso. Nos discursos dos participantes da pesquisa, estiveram presentes aspectos éticos relacionados à falta de liberdade de escolha, à falta de informação disponível aos usuários sobre os produtos fluorados e sobre o controle dos níveis de flúor nesses produtos. Houve também quem acreditasse que o custo-benefício da fluoretação supera qualquer aspecto ético que possa estar presente. Questões éticas são frequentemente vistas pelos participantes da pesquisa como algo desconhecido ou complexo. Existe a crença de que a população em geral está despreparada para discutir o assunto com propriedade, já que este é mais bem compreendido pela parcela da sociedade composta por gestores e profissionais de saúde. Não houve consenso quanto à presença ou não de fatores éticos no uso de produtos fluorados.

> Palavras-chave: fluoretação; água fluoretada; ética; saúde pública.

\author{
1 Faculdade de Farmácia, \\ Odontologia e Enfermagem, \\ Universidade Federal do Ceará. \\ Fortaleza-CE, Brasil. Endereço \\ eletrônico: reginalucena1@ \\ hotmail.com \\ 2 Secretaria Municipal de Saúde \\ de São Paulo. São Paulo-SP, \\ Brasil. Endereço eletrônico: \\ regina.a.marques@uol.com.br \\ ${ }^{3}$ Faculdade de Farmácia, \\ Odontologia e Enfermagem, \\ Universidade Federal \\ do Ceará. Fortaleza-CE, \\ Brasil. Endereço eletrônico: \\ Ibezerrademenezes@yahoo. \\ com.br \\ ${ }^{4}$ Universidade de São Paulo. \\ São Paulo-SP, Brasil. Endereço \\ eletrônico: pcnarvai@usp.br
}

Recebido em: 18/09/2013 Aprovado em: 11/06/2014 


\section{Introdução}

A palavra "ética" vem do grego ethos, que significa "morada; lugar onde vivemos". Mais tarde, ela passou a significar o "caráter", o "modo de ser" que uma pessoa ou grupo adquire ao longo da vida. Diz respeito aos costumes, condutas, regras de comportamento, modo de ser, como resultado de se pôr em prática determinados costumes ou hábitos considerados bons (FORTES; ZOBOLI, 2008).

A ética da saúde, enraizada no terreno dos direitos humanos, se preocupa com valores relacionados com a manutenção da saúde e a qualidade de vida das pessoas, o que implica deveres e obrigaçôes individuais e institucionais (FORTES; ZOBOLI, 2008). Nesse contexto, Schramm e Kottow (2001) definem a bioética da proteção como "uma ética da responsabilidade social, em que se deve basear o Estado para assumir suas obrigações sanitárias para com as populações humanas, consideradas em seus contextos reais" (PONTES; SCHRAMM, 2004, p. 1.321).

Para proteger a coletividade, muitas vezes as ações de saúde pública restringem liberdades e direitos individuais, como é o caso da fluoretação das águas para o consumo humano. Não obstante essa medida ter reconhecida eficácia para prevenir a cárie dentária (HOROWITZ, 1996), ela pode provocar fluorose dentária, e vem sendo objeto de intensas discussões éticas (MENDOZA, 2007; KALAMATIANOS; NARVAI, 2006).

O princípio utilitarista afirma que as ações são eticamente corretas quando tendem a promover a maior soma de prazer a todos aqueles cujos interesses estão em jogo. Tem como paradigma: o alcance do "maior bem-estar para o maior número possível de pessoas ou para a maximização do seu bem-estar." Nessa visão utilitarista, a saúde pública, que não dispõe tecnicamente de meios simplificados e práticos para separar água com flúor e água sem flúor, impõe a primeira a todos, em prol da coletividade, ponderando os benefícios para muitos e os riscos de danos para alguns (FORTES; ZOBOLI, 2008).

As medidas de vigilância sanitária também seguem esse princípio, ajustando os interesses da coletividade em nome da supremacia do interesse público sobre o individual, priorizando os princípios da beneficência e da não maleficência sobre outros princípios éticos, como o da autonomia individual (FORTES; ZOBOLI, 2008). Coggon e Cooper (1999) enfatizam, entretanto, que como os mais beneficiados com a fluoretação da água nem sempre são os mais necessitados (os 
mais expostos ao risco), qualquer tentativa de balancear ou equilibrar beneficência e autonomia torna-se ainda mais complexa.

O debate sobre os aspectos éticos relacionados ao uso do flúor quase sempre se limita à fluoretação das águas de abastecimento público. Teores inadequados de flúor em águas têm implicações éticas, por isso é de fundamental importância se conhecer o teor natural de flúor das águas de um determinado manancial, antes de disponibilizá-las ao consumo humano. No caso de a água ser hipofluorada, o efeito protetor contra a cárie será prejudicado, devendo a população ser informada. Por outro lado, se a água é hiperfluorada, a população com idade até nove anos corre o risco de desenvolver fluorose dentária. Em nenhuma hipótese, se deve fornecer à população uma água cujo teor de flúor seja desconhecido (NARVAI; BIGHETTI, 2008).

No debate sobre a fluoretação das águas de abastecimento público, aqueles que se posicionam contra a medida utilizam argumentos diversos, como a associação entre os fluoretos e fluorose dentária, câncer, osteoporose e fratura óssea (BASSIN et al., 2006; COOPER et al., 1990). A restrição da liberdade individual e a violação do direito à livre escolha também são argumentos utilizados pelos opositores da fluoretação da água para consumo (CROSS; CARTON, 2003; COHEN; LOCKER, 2001). Há ainda quem veja a medida como um procedimento de medicação em massa, violando os direitos humanos dos indivíduos de não serem submetidos a intervenções médicas sem consentimento prévio (CROSS; CARTON, 2003).

Mendoza (2007), entretanto, se opõe a esse pensamento, uma vez que a fluoretação das águas é uma tecnologia de saúde pública que visa tão somente ajustar o teor de fluoreto existente em qualquer água, com a finalidade de que esse teor seja compatível, em águas de abastecimento público, com a prevenção da cárie. A eficácia e segurança dessa tecnologia para a saúde humana foram comprovadas por vasta literatura científica (JONES et al., 2005). Além disso, a fluoretação das águas pode ser vista como uma medida eticamente adequada, pois responde a um problema de saúde pública - a cárie dentária, reduzindo sua prevalência, com custo-efetividade, cujos riscos são conhecidos, sustentáveis e aleatórios. O fato de populações vulneráveis serem beneficiadas justifica a limitação da autonomia individual (MENDOZA, 2007; McNALLY; DOWNIE, 2000). 

são postas diante dos formuladores de políticas e tomadores de decisão, mas a população, cuja saúde e bem-estar influenciam sobremaneira a tomada de decisão, geralmente permanece alheia a essa situação.

Sabendo-se que existem questões éticas relacionadas ao uso do flúor, o objetivo deste estudo é conhecer as percepções dos delegados na $13^{\text {a }}$ Conferência Nacional de Saúde sobre os aspectos éticos relacionados ao uso de substâncias e produtos fluorados, em especial sobre a fluoretação das águas. Admite-se, em termos metodológicos, que o pensamento desses atores sociais sobre esse assunto seja um indicativo qualitativo do que pensam os segmentos da população brasileira por eles representados.

\section{Método}

Este estudo faz parte de uma pesquisa sobre a fluoretação das águas de abastecimento público, junto aos delegados da $13^{\text {a }}$ Conferência Nacional de Saúde (2007). Trata-se de uma pesquisa descritiva, de natureza qualitativa, que consistiu na aplicação de questionário semiestruturado contendo 19 questōes sobre o uso do flúor em saúde pública, com foco na fluoretação das águas. A coleta dos dados se deu durante as etapas municipal (Fortaleza), estadual (Ceará) e nacional (Brasília) da Conferência.

Por se tratar de um estudo qualitativo, não houve preocupação em constituir uma amostra representativa da população estudada, tendo sido esta definida por conveniência. Participaram os delegados que, ao serem abordados e ouvirem os objetivos do estudo, concordaram em responder ao questionário, mediante a assinatura do Termo de Consentimento Livre e Esclarecido. O critério de escolha foi participar da conferência como delegado, e o de exclusão foi já ter respondido ao questionário em etapa anterior da conferência. A pesquisa foi aprovada pelo Comitê de Ética em Pesquisa da Faculdade de Saúde Pública da Universidade de São Paulo, sob o Parecer no 1.723.

Participaram 310 delegados, de ambos os sexos, com idade entre 18 e 76 anos, distribuídos da seguinte maneira: 56 da etapa municipal (Fortaleza), 143 da etapa estadual (Ceará) e 111 da nacional (Brasília). A distribuição, por segmento, foi a seguinte: 72 gestores/prestadores de serviços de saúde, 91 trabalhadores de saúde e 147 usuários. 
Com o intuito de se conhecer as percepções dos delegados sobre os aspectos éticos envolvidos no uso de substâncias e produtos com flúor, a seguinte pergunta foi formulada: "Na sua opinião, há algum aspecto ético envolvido na utilização de produtos ou substâncias que contêm flúor?"

Para o tratamento dos dados, foi utilizada a técnica do Discurso do Sujeito Coletivo - DSC, que consiste num conjunto de procedimentos de tabulação e organização de dados discursivos, provenientes de depoimentos orais ou não (TEIXEIRA; LEFÈVRE, 2008). O DSC permite que determinado grupo social seja visto como autor e emissor de discursos comuns, compartilhados entre seus membros.

Identificadas as expressões-chave, que são segmentos contínuos ou descontínuos dos discursos que revelam o principal conteúdo discursivo, elas foram agrupadas conforme a ideia central que expressavam. Os discursos-síntese (DSC) relativos a cada ideia central foram elaborados a partir dos depoimentos literais (LEFÈVRE et al., 2000).

Os discursos do sujeito coletivo foram analisados utilizando-se, como estratégia metodológica, a análise do discurso, que leva em consideração a cultura, o contexto e as intenções dos sujeitos. $\mathrm{O}$ encontro entre sujeitos historicamente contextualizados e socialmente determinados, com diversidades culturais e subjetividades, permitiu compreender o discurso de um sujeito coletivo histórico e socialmente determinado, evidenciando-se elementos que podem servir de subsídios para o redirecionamento das práticas sanitárias.

\section{Resultados}

Os discursos evidenciaram ideias centrais contendo aspectos éticos de diversas naturezas, assim considerados pelos delegados participantes do estudo, como se pode ver a seguir.

\section{Ideia Central 1: Fatores éticos relacionados ao controle dos níveis de flúor contido nos produtos e substâncias fluorados DSC 1 - Gestor/prestador:}

Toda política e programa deverá passar por parecer ético, para ser validado, nessa questão também há aspectos éticos envolvidos e que exigem fiscalização e controle rigorosos nos procedimentos. Deve existir a ética da responsabilidade do cuidado. 
Acho que a fluoretação deve ser feita por profissionais com capacidade e consciência de sua responsabilidade e com uma política de governo segura e responsável para todo seu povo, garantindo o monitoramento do volume de flúor, para evitar danos à saúde. Devemos priorizar e exigir das autoridades mais fiscalização.

\section{DSC2 - Trabalhador de Saúde:}

A questão ética refere-se aos níveis de flúor nos produtos, que devem ser monitorados conforme a região do país. Os produtos são utilizados indiscriminadamente, muitas vezes sobrepondo as doses. Ex: creme dental, flúor no consultório, flúor na água potável, fluoretação semanal na escola. Deve haver o controle da vigilância sanitária no aspecto do teor do flúor e qualidade do flúor. O princípio ético se vincula à responsabilidade cívico-social de que as normas técnicas e padrões científicos sejam respeitados e que a sociedade reconheça as formas de controle e fiscalização e instâncias de denúncia. Acredito que a questão da autonomia do usuário quanto à utilização não fica prejudicada quando há o monitoramento pelos órgãos competentes, sem riscos à saúde, só benefícios.

\section{DSC3 - Usuário:}

Como todo medicamento, o uso de flúor deve ser indicado por profissional qualificado (dentista) na forma, concentração e frequência adequados. Se for usado demais, prejudica. Tem de ser o dentista que orienta. Deve haver muita responsabilidade pela pessoa que vai fazer essa fluoretação. Há propaganda, mas a coisa não é feita com seriedade. "Não tem a quantidade de flúor correta no creme dental. Olhe! Tudo que é mal feito para ser entregue grátis ou vendido ao usuário sem um controle rígido da dosagem é um GRANDE DESRESPEITO”.

\section{Ideia Central 2: Fatores éticos relacionados à falta de informação aos usuários acerca dos produtos e substâncias fluorados DSC1 - Gestor:}

As pessoas têm o direito de ser informadas acerca do que estão consumindo. Não se pode decidir algo sem a opinião das pessoas envolvidas no processo. Além disso, deve se ter ética e cuidado na hora em que se vai utilizar o produto, para não vir a prejudicar a pessoa/população. $\mathrm{O}$ acesso à informação deve ser garantido para todos os usuários desses produtos e os benefícios e riscos envolvendo o uso inadequado, o excesso ou a carência da substância. Não é divulgada a quantidade de flúor, indicações e contraindicações. Em excesso, faz mal. Não entendo porque não é repassado para a população sobre os verdadeiros malefícios que o flúor causa, só é mostrada a necessidade do seu uso na prevenção da cárie, e os males?"

\section{DSC2 - Trabalhador de Saúde:}

Por desconhecermos os efeitos, não sabemos se é benéfico ou maléfico no consumo, tão pouco as quantidades ou qualidades que não exponham a população a riscos. 

DSC1 - Gestor:

À medida que estamos analisando os prós e os contras, a importância, a situação, quem paga, a quem interessa, estamos discutindo os aspectos éticos. Há interesses de lobistas e de empresas multinacionais. Além disso, talvez seja mais lucrativo para a classe de dentistas não haver controle do flúor, pois a doença, ainda, é vista como rentável. Profissionais de saúde ainda estão sendo formados para trabalhar com a doença e o flúor, em níveis adequados, previne que agravos aconteçam. É preciso pensar Saúde! Uma comunidade saudável produz e vive melhor e esse é o princípio ético que deve ser pensado ao votar projetos de lei ou formar profissionais de saúde.

\section{DSC2 - Trabalhador de Saúde:}

O que se percebe com relação à utilização do flúor, são as opiniōes de pessoas sem nenhum envolvimento com essa problemática, levando a questão para um plano meramente político e econômico, desviando desta forma o eixo científico da discussão. Não podemos usar o argumento de benefício para a população para beneficiar a indústria produtora de flúor e privilegiar a lógica do mercado.

DSC3 - Usuário:

A falta de ética na sociedade leva a abusos quase sempre em função de interesses econômicos.

\section{Ideia Central 4: Fatores éticos relacionados ao direito do ser humano à livre escolha}

\section{DSC1 - Trabalhador de Saúde:}

Acredito que são medidas que podem influenciar a vida humana, portanto deverão seguir aspectos éticos. A ética está atrelada a todo processo humano. Deve ser mais claro, discutido e aberto à comunidade. Deve atender os princípios da bioética: beneficência, da não maleficência e da vontade expressa do indivíduo em submeter-se à exposição (não me lembro o nome deste princípio...). As pessoas têm direito de decidir o que consideram benéfico para si. Há ideia de que a fluoretação da água não daria à população a opção de consumo de flúor. Não haveria a livre escolha. Seria um consumo de flúor muitas vezes compulsório. Se a ciência propuser a colocação de outras substâncias, como a população poderá questionar?

\section{Ideia Central 5: Fatores éticos relacionados à "vontade política" e "consciência" dos governantes \\ DSC1 - Gestor:}

Essa é uma implementação que deveria ser abraçada por todos os responsáveis pela gestão pública, já que isso acarretaria uma melhor qualidade de vida para todos. De- 
vemos proporcionar acesso a todos os produtos em níveis adequados para evitarmos doenças, se sabemos que faz bem devemos proporcionar isso à população, não podemos nos omitir. $\mathrm{O}$ que existe é falta de vontade, pois dinheiro, recurso tem e muito.

\section{DSC2 - Trabalhador de Saúde:}

Acho que falta vontade política e consciência dos próprios governantes em benefício da população. Se se colocassem no lugar da população carente...

\section{Ideia Central 6: $\mathrm{O}$ custo-benefício supera as questōes éticas DSC1 - Trabalhador de Saúde:}

O flúor é uma substância que foi comprovado cientificamente atuar na prevenção e combate à cárie. Tudo que é benefício deve ser bem aceito, desde que seja decidido com a participação da população. O custo/benefício supera qualquer discussão sobre o assunto.

\section{DSC2 - Usuário:}

Toda ação pública que reveste em melhor qualidade de vida e saúde para a população é sinônimo de ÉTICA. O aspecto ético é o da observância do predomínio do bem estar coletivo em detrimento de alguns que eventualmente são contrários à adição do flúor na água disponibilizada à população. Existem opções aos que são contrários. Os benefícios superam qualquer fator ético ou político.

\section{Ideia Central 7: Desconhecimento sobre o assunto DSC1-Gestor:}

Não sei opinar. Não tenho conhecimento nem propriedade sobre o assunto, pois ele fica restrito a algumas pessoas ou secretários, mas a ética tem que estar presente em todas as áreas. A partir de hoje, pretendo me informar mais.

\section{DSC2 - Trabalhador de Saúde:}

A utilização do flúor não é algo que tenha um conhecimento específico, pois, foge um pouco da minha área, portanto, estas respostas são superficiais. Eu precisaria conhecer mais o assunto para poder opinar. Até onde eu sei, só traz benefícios. A melhor pessoa para responder este aspecto são os odontólogos.

\section{DSC3 - Usuário:}

Deve existir, não sei explicar. Não comentarei sobre ética, é muito complexo. Não tenho conhecimento de nenhuma publicação a respeito. Não posso opinar, pois não conheço. 


\section{Discussão}

"Aspetos éticos" diversos foram citados pelos delegados, especialmente aqueles relacionados ao controle dos níveis de flúor, à falta de informação sobre os produtos fluorados, aos interesses econômicos e ao direito à livre escolha. Houve, entretanto, quem considerasse que a autonomia individual não é prejudicada, desde que haja benefícios para a população.

Observa-se que há uma preocupação por parte dos delegados acerca da manutenção dos teores de flúor adequados nos produtos e substâncias fluorados, o que é procedente, uma vez que a eficácia preventiva da fluoretação das águas depende da adequação do teor de flúor e da continuidade do processo (NARVAI et al., 2004). Cury e colaboradores (2004) lamentam que, em algumas cidades, o controle da fluoretação não tem a continuidade necessária e, frequentemente, os níveis de flúor da água ficam abaixo dos recomendados, privando a população dos benefícios da medida. Por outro lado, níveis de flúor acima dos recomendados podem ocasionar efeitos adversos, dentre eles, a fluorose dentária (LEVY, 1994). Esta constitui um problema relevante de saúde pública, pois em suas formas moderada e severa, provoca alteraçôes funcionais e estéticas. Nos estágios avançados, essas alterações podem interferir na inserção da pessoa no mercado de trabalho podendo, em alguns casos, exigir tratamento odontológico complexo (CANGUSSU et al., 2002).

Vários estudos revelaram teores inadequados de flúor na água e/ou descontinuidade da fluoretação (SALIBA et al., 2006; MOURA et al., 2005; LIMA et al., 2004; MAIA et al., 2003). Parece que há dificuldade em se manter sistemas operacionais de monitoramento dos níveis ótimos de flúor na água (NARVAI, 2000). Isso aponta para a falta cobrança da sociedade e indica fragilidades no controle social relativo a essas questôes.

No controle e no monitoramento dos níveis de flúor nos produtos e substâncias que consomem, os delegados se referem ao papel protetor do Estado baseado no "princípio de proteção", que é considerado por alguns como o mais adequado para abordar os problemas morais relacionados à saúde pública (PONTES; SCHRAMM, 2004).

Segundo Kalamatianos e Narvai (2006), o princípio da proteção, associado às evidências sobre a eficácia e a necessidade de certas ações de alcance coletivo, e o 
princípio da precaução, relativo aos danos e riscos potenciais advindos dessas ações, frequentemente estão presentes quando os formuladores de políticas públicas e os tomadores de decisões em saúde encontram-se em situações de conflito.

Usuários e trabalhadores de saúde consideram a falta de acesso à informação sobre o flúor que é posto nos produtos, inclusive na água, um aspecto ético importante. Outros estudos também constataram a falta de informação da população a respeito da água de abastecimento, havendo necessidade de melhor divulgação de informações pertinentes ao assunto. Embora exista um sistema de informação, muitas vezes faltam transparência e acesso da população às informaçōes acerca do monitoramento da qualidade da água (KALAMATIANOS; NARVAI, 2006; BLEICHER; FROTA, 2006; JONES et al., 2005; LOWRY; ADAMS, 2004).

De fato, é um problema de natureza ética não informar sobre o teor de flúor da água, antes de disponibilizá-la para a população. As pessoas devem ser informadas sobre a água que consomem, sendo obrigação do governo manter a população informada mediante mecanismos acessíveis de divulgação, inclusive com a participação das companhias de saneamento (BRASIL, 2005). No monitoramento e controle dos teores e flúor na água, não houve referência à participação do consumidor, que parece ter um papel passivo, de receptor submisso, o que denota uma lacuna relativa ao papel da comunidade na vigilância sanitária externa (heterocontrole) e fragilidades no controle social.

A mercantilização é considerada também um aspecto ético, na concepção de gestores, usuários e trabalhadores de saúde, que acreditam que há interesses econômicos de alguns grupos. No tratamento da água, a que todos têm direito, há custos envolvidos, mas o acesso universal não deve ser dificultado ou impedido por esses interesses. Numa sociedade capitalista, em que quase tudo se submete à lógica de mercado, certamente existe uma parcela da sociedade que não tem acesso a dentifrícios e a outros produtos fluorados, o que dá ênfase à fluoretação das águas de abastecimento como a medida de maior alcance populacional, independentemente do nível socioeconômico.

A falta de "vontade política" dos governantes para investir na fluoretação, privando a sociedade desse benefício, é uma questão ética, na opinião dos três segmentos de delegados. Para Narvai e colaboradores (2004), mais do que uma "vontade política", a fluoretação das águas das águas de abastecimento público 
no Brasil deve ser considerada um direito de cidadania, direcionando-se esforços para ampliar sua cobertura.

Não obstante a "restrição à liberdade de escolha" ser um dos principais argumentos utilizados por aqueles que se posicionam contra a fluoretação da água de abastecimento público, esse aspecto surgiu apenas no DSC do trabalhador da saúde. Em estudo sobre aspectos éticos do uso de produtos fluorados no Brasil, Kalamatianos e Narvai (2006) mencionam não ter havido qualquer referência à restrição da autonomia individual.

Para Mendoza (2007) a fluoretação da água deve ser vista numa perspectiva bioética, já que, ao se abordarem problemas coletivos, as medidas de saúde pública devem respeitar a equidade de acesso e assegurar a obtenção de benefícios para a sociedade, ainda que esses restrinjam, em certo grau, a autonomia individual. Essa autora julga necessário desenvolver uma ética própria da saúde pública, baseada na ética da proteção, considerando o caráter coletivo da saúde pública.

Kalamatianos e Narvai (2006) enfatizam que as decisōes sobre o uso de produtos fluorados têm de ser tomadas no plano político, no qual qualquer decisão atende a certos interesses, contrariando outros. Decidir que interesses devem ser contrariados em cada contexto põe em destaque a importância dos valores democráticos e as relações entre saúde e democracia.

Identificaram-se questões éticas no uso de substâncias e de produtos fluorados, entretanto, entre os delegados, não existiu um consenso. Houve também quem não pudesse opinar, por falta de conhecimento sobre o assunto. Acredita-se que, em alguns casos, essa insegurança ou impossibilidade de emitir opinião pode ter sido ocasionada pela falta de compreensão da expressão "aspectos éticos", o que pode constituir uma limitação deste estudo. Por outro lado, alguns consideraram que os benefícios proporcionados pela fluoretação (prevenção e combate à cárie e melhoria na qualidade de vida) superam os fatores éticos, o que denota o reconhecimento da importância da medida por esses atores.

\section{Consideraçôes finais}

No contexto brasileiro e em outros, nos quais as disparidades nos níveis de cárie entre os grupos com diferentes situações socioeconômicas são significativas, leva-se a crer que não existam problemas éticos em se utilizar medidas que 
disponibilizem o flúor ao maior número possível de pessoas, pautando-se na visão utilitarista. Recomenda-se, entretanto, que as pessoas sejam informadas sobre os benefícios da medida e seus possíveis riscos.

Questôes éticas frequentemente são vistas como algo desconhecido ou complexo. Neste estudo, percebe-se esse ponto de vista, além da ideia de que a população, em geral, está despreparada para discutir o assunto com propriedade, já que esse é mais bem compreendido pela parcela da sociedade composta por profissionais de saúde e gestores. ${ }^{1}$

\section{Referências}

BASSIN, E.B. et al. Age-specific fluoride exposure in drinking water and osteosarcoma (United States). Cancer Causes Control, v. 17, n. 4, p. 421-428, 2006.

BLEICHER, L.; FROTA, F.H.S. Fluoretação da água: uma questão de política pública: o caso do Estado do Ceará. Ciênc Saúde Coletiva, Rio de Janeiro, v. 11, n. 1, p. 71-78, 2006. . BRASIL. Decreto no 5.440, de 5 de maio de 2005. Estabelece definiçôes e procedimentos sobre o controle de qualidade de sistemas de abastecimento e institui mecanismos e instrumentos para divulgação de informação ao consumidor sobre a qualidade da água para consumo humano. Diário Oficial da república Federativa do Brasil, Brasília, DF, 5 maio 2005. Disponível em: <http://www.planalto.gov.br/ccivil_03/ato2004-2006/2005/ decreto/d5440.htm>. Acesso em: 5 abr. 2006.

CANGUSSU, M.C.T. et al. A. Fluorose dentária no Brasil: uma revisão crítica. Cad Saúde Pública, Rio de Janeiro, v. 18, n. 1 p. 7-15, 2002.

COGGON, D.; COOPER, C. Fluoridation of water supplies: Debate on ethics must be informed by sound science. BMJ, London, v.319, n.7.205, p. 269-270, 1999.

COHEN, H.; LOCKER, D. The science and ethics of water fluoridation. J Can Dent Assoc, v. 67, n. 10 , p. 578-580, 2001.

COOPER, C. et al. Water fluoridation concentration and fracture of the proximal femur. $J$ Epidemiol Community Health, London, v. 44, n. 1, p. 17-19, 1990.

CROSS, D.W.; CARTON, R.J. Fluoridation: a violation of medical ethics and human rights. Int J Occup Enviroment, v. 9, n. 1, p. 24-29, 2003.

CURY, J.A. et al. The importance of fluoride to the current dental caries prevalence in Brazil. Rev Dent J, Ribeirão Preto, v. 15, n. 3, p. 167-174, 2004.

FORTES, P.A.C.; ZOBOLI, E.L.C.P. Ética na saúde pública. In: ROCHA, A.A.; CHESTER, L.G.C. (Org.). Saúde pública bases conceituais. São Paulo: Atheneu, 2008. p. 197-209. 
HOROWITZ, H.S. The effectiveness of community water fluoridation in the United States. J Public Health Dent, v. 56, n.(spec. n.), p. 253-8, 1996.

JONES, S.; BURT, B.A.; PETERSESN, P.E. The effective use of fluorides in public health. Bull World Health Organ, Geneva, v. 83, n. 9, p. 670-676, 2005.

KALAMATIANOS, P.A.; NARVAI, P.C. Aspectos éticos de produtos fluorados no Brasil: uma visão dos formuladores de políticas de saúde. Ciênc Saúde Coletiva, Rio de Janeiro, v. 11, n. 1, p. 63-69, 2006.

LEFÈVRE, F.; LEFÈVRE, A.M.C.; TEIXEIRA, J.J.V. O discurso do sujeito coletivo: uma nova abordagem metodológica em pesquisa qualitativa. Caxias do Sul: EDUCS; 2000.

LEVY, S.M. Review of fluoride exposures and ingestion. Community Dent Oral Epidemiol, v. 22, n. 1, p. 73-80, 1994.

LIMA, F.G. et al. Vinte e quatro meses de heterocontrole da fluoretação das águas de abastecimento público de Pelotas, Rio Grande do Sul, Brasil. Cad Saúde Pública, Rio de Janeiro, v. 20, n. 22, p. 422-429, 2004.

LOWRY, R.L.; ADAMS, G. Attitudes to water fluoridayion in general dental practice in the North East of England. Br Dent J., Ribeirão Preto, v. 196, n. 7, p. 423-424, 2004.

MAIA, L.C. et al. Controle operacional da fluoretação da água de Niterói, Rio de Janeiro, Brasil. Cad Saúde Pública, Rio de Janeiro, v. 19, n. 1, p. 61-67, 2003.

MCNALLY, M.; DOWNIE, J. The etics of water fluoridation. J Can Dent Assoc, v. 66, n. 11, p. 592-593, 2000.

MENDOZA, C. El dilema ético de la fluoración del água potable. Rev Méd Chile, Santiago, v. 135, n. 11, p. 1487-1493, 2007.

MOURA, M.S. et al. Avaliação longitudinal da fluoretação da água de abastecimento público de Teresina/PI. Rev. Odonto Ciênc, Porto Alegre, v. 20, n. 48, p. 132-136, 2005.

NARVAI, P.C. Cárie dentária e flúor: uma relação do século XX. Cienc. Saúde Coletiva, Rio de Janeiro, v. 5, n. 2, p. 381-392, 2000.

NARVAI, P.C.; BIGHETT,I T.I. Fluorose dentária: aspectos epidemiológicos de vigilância à saúde. In: PINTO, V.G. (Org.). Saúde Bucal Coletiva. São Paulo: Santos, 2008. p. 228-243.

NARVAI, P.C.; FRAZÃO, P.; FERNANDEZ, R.A.C. Fluoretação da água e democracia. Saneas, São Paulo, v. 2, p. 29-33, 2004.

PONTES, C.A.A.; SCHRAMM, F.R. Bioética da proteção e papel do estado: problemas no acesso desigual á água potável. Cad Saúde Pública, Rio de Janeiro, v. 20, n. 5, p. 13191327, 2004.

SALIBA, N.A.; MOIMAZ, S.A.S.; TIANO, A.V.P. FLuoride level in public water supplies of cities from the northwest region of São Paulo state, Brazil. J Appl Oral Sci, v. 14, n. 5, p. 346-350, 2006. 
SCHRAMM, F.R.; KOTTOW, M. Princípios bioéticos en salud publica: limitaciones e propuestas. Cad Saúde Pública, Rio de Janeiro, v. 17, n. 4, p. 949-956, 2001.

TEIXEIRA, J.J.V.; LEFÈVRE, F. Significado da intervenção médica e da fé religiosa para o paciente idoso com câncer. Ciênc Saúde Coletiva, Rio de Janeiro, v. 13, n. 4, p. 1247-1256, 2008.

\section{Nota}

${ }^{1}$ R.G.R. de Lucena e P.C. Narvai participaram de todas as etapas, desde a concepção do projeto até a redação final do artigo e aprovação da sua versão final. R.A.A. Marques e L.M.B. de Menezes participaram da redação do artigo, revisão crítica relevante do conteúdo intelectual e aprovação final da versão a ser publicada. 
Ethical aspects and the use of fluoride products in the viewpoint of health leaders

Fluoride has been used in the prevention of dental caries, especially in drinking water and toothpaste. An undesirable effect, mild fluorosis, has raised concerns among experts. This paper describes the perceptions of the delegates at the 13th Brazilian National Health Conference concerning ethical issues related to the use of substances and fluorinated products. We conducted exploratory, descriptive study with a qualitative approach, using as processing technique testimonials the Collective Subject Discourse (CSD). The study population was defined by convenience, and the choice criterion was attending the conference as a delegate. In all, there were 310 respondents. Data were collected through semistructured questionnaires and analyzed by discourse analysis. In the speeches of participants, there were ethical aspects related to the lack of freedom of choice, the lack of information available to users on fluorinated products and the control of fluoride levels in these products. Also there were people who believed that the cost-effectiveness of fluoridation outweighs any ethical aspect that may be present. Ethical issues are often seen by the research participants as something unknown or complex. There is the belief that the general population is unprepared to discuss it properly, as this is best understood by managers and health professionals. There was no consensus as to the presence or absence of ethical factors in the use of fluorinated products.

Key words: fluoridation; fluoridated water; ethics; public health. 